\title{
Construction of Fuzzy Inference System for Public Food Supply Chain in cooperative Sector
}

\author{
Dr.G.Ayyappan ${ }^{1}$, Dr.K.Alice Suresh ${ }^{2}$, Dr.S.Thirunavukkarasu ${ }^{3}$, Dr.A.Kumaravel ${ }^{4}$ \\ Associate Professor ${ }^{1,2,3}$, Professor \& Dean School of Computing ${ }^{4}$ \\ Department of Information Technology ${ }^{1,2,3,4}$ \\ Bharath Institute of Higher Education and Research, BIHER,Bharath Unviersity, Chennai. 1,2,3,4
}

\begin{abstract}
The currently going on demand for digitalization public supply chains in cooperative sectors motivates to go for metrics which raise the fairness and at the same time the standards of the Government either regional or federal synchronizing with their policies and legislation towards economic growth and citizen welfare. The involved decision makers cannot be rigid/discrete in measuring the parameters in such systems and hence fuzzy logic is identified suitable for them. Though there are many research works in the literature, still their focus is on particularly on systems managing safety, risk and profit outputs. The lack of availability of this approach in cooperative sectors for public food distribution makes the authors to propose a fuzzy inference system accommodating fuzzy rules mapping to Farmers yield, Government approval rate and customer Demand
\end{abstract}

Keywords: Supply Chain, Fuzzy Inference System. Public Cooperative Sector, Fuzzy Membership functions, Fuzzy rule based system.

\section{Introduction}

The priority for system design usually tends to give results with correctness as well as unbiased fairness. A system in which people and government participate must be based on extensive research for designing and developing its components. The governance [5] may be based on formal verification by sound principles or aggregated using well established previously available systems. The fuzzy logic is favoured by the research community due to its flexibility in measurement of imprecise values as seen $[11,12]$.The previous work for integrating system $[1,2,3]$ approach in supply chain issues. In common the design of fuzzy systems is depending on the experts' opinions for fixing the intervals and their bounds to implement fuzzy membership functions of the attributes participating as inputs and outputs. Here three entities farmer, customer and government are identified and being extracted the relevant attributes.

This paper is organized with seven section as follows: section 2 design and development of targeted fuzzy inference, section 3 Linguistic variables for Farmer Entity, section 4 Linguistic variables for Farmer Government Entity, section, Section 5 Description of Linguistic variables for Customer Entity, Section 6 Generation Rule Base, finally section 7 for conclusion and remarks.

\section{Methods and Materials}

In order to decrease resources intake and decision making, Fuzzy logic is used. Fuzzy linguistic variables are obtained by transforming a crisp input variable by a fuzzifier [1]. Membership function plays a vital role in this shifting. An input variable can be linked to one or more fuzzy sets depending on the calculated membership degrees.

For instance we come across two terms warm and cold from the value of temperature. Next, the fuzzified values are processed by ifthen statements according to a set of predefined rules provided by experts. In this stage, the inference scheme relates input fuzzy sets for outputs fuzzy sets. At last, Fuzzy set outputs are defuzzified and crisp outcomes are obtained. Thus the fuzzy logic is executing control systems through a rule-based system 


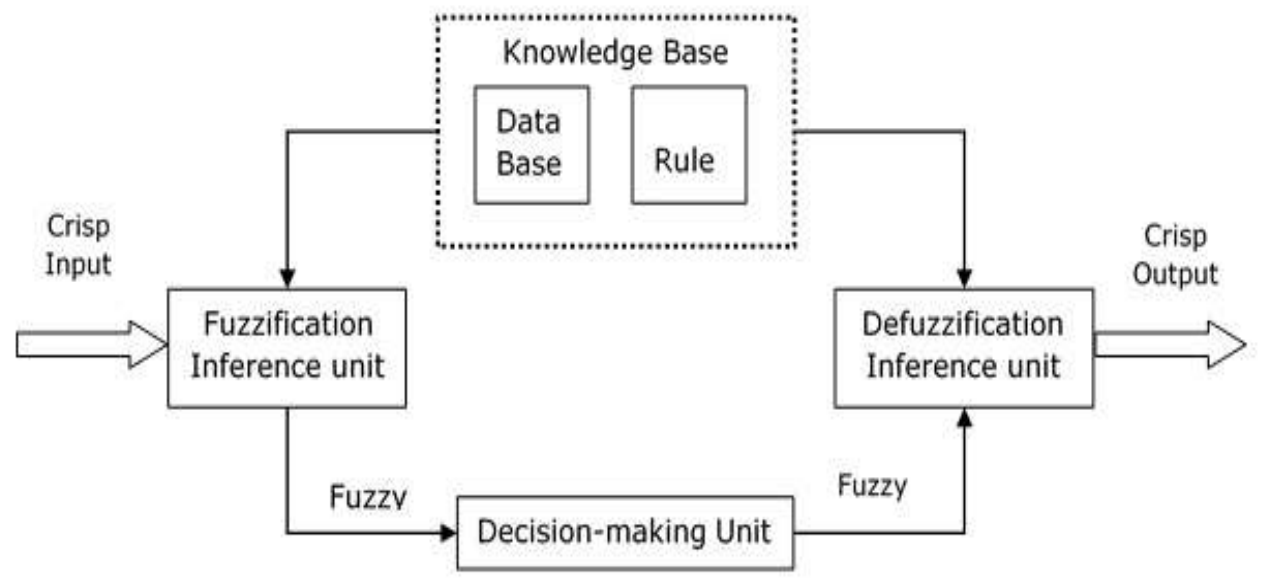

Figure 1. General Fuzzy Inference System

In Fig 1, the connected components show the input to output flow as crisp input to crisp output, but transform into fuzzified values by fuzzifier and retransfored into crisp value again by a defuzzifier. In order to get the output the rule base gets fired depending on the fuzzified input values. The mapping of output is determined by the aggregation of appropriate rule and fuzzy relational operators implemented in MatLab.

The tool for design and development of targeted fuzzy inference systems is selected over MATLAB fuzzy components.

The table 1 below shown carries the metadata for attributes connected to farmer entity

Table 1.Description of Linguistic variables for Farmer Entity

\begin{tabular}{|l|l|l|l|}
\hline Farmer Mamdani Fuzzy Inference System & \\
\hline Attribute Values & Linguistic Variable Values & Range & Input/Output \\
\hline Farm Land & Small,Medium ,High & $1-30$ Acres & Input \\
\hline Manpower & Small,Medium ,High & $1-60$ & Input \\
\hline Seed & Low,Medium ,High & $1-5$ quintals & Input \\
\hline Yields & Small,Medium ,High & $1-1000$ quintals & output \\
\hline
\end{tabular}

The table 2 below shown carries the metadata for attributes connected to government entity

Table 2 Description of Linguistic variables for Government Entity

\begin{tabular}{|l|l|l|l|}
\hline \multicolumn{2}{|l|}{ Government Mamdani Fuzzy Inference System } & \\
\hline Attribute Values & Linguistic Variable Values & Range & Input/Output \\
\hline Farmer Supply & Small,Medium ,High & $1-1000$ quintals & Input \\
\hline Customer Demand & Small,Medium ,High & $1-10$ quintals & Input \\
\hline Approval Rate & Small,Medium ,High & $1-100$ & output \\
\hline
\end{tabular}

The table 3 below shown carries the metadata for attributes connected to Customer entity

Table 3 Description of Linguistic variables for Customer Entity

\begin{tabular}{|l|l|l|l|}
\hline \multicolumn{2}{|l|}{ Customer Mamdani Fuzzy Inference System } & \\
\hline Attribute Values & Linguistic Variable Values & Range & Input/Output \\
\hline Family Size & Small,Medium ,High & $1-10$ quintals & input \\
\hline Family Income & Small,Medium ,High & $1-100000$ Rupees & Input \\
\hline Family Need & Small,Medium ,High & $1-10$ quintals & Input \\
\hline Demand & Small,Medium ,High & $1-10$ quintals & output \\
\hline
\end{tabular}




\section{Generation Rule Base and Results}

The rule base is designed for significant selection of input values from the solution space of $\left(3^{3}+3^{3}+2^{3}\right)=62$ combinations. Even though the three subsystems are designed separately its functionality works concurrently for farmers and consumers and sequentially with Government fuzzy subsystem. The following rule base lists show three segments of the rule base followed by the different views of specific sample outputs .

\section{Farmer Rules Fuzzy Subsystem}

1. If (Farmer.Farmland is small) and (Farmer.Manpower is LoW) and (Famer.Seed is small) then (Farmer.Yield is Small) (1)

2. If (Farmer.Farmland is small) and (Farmer.Manpower is Medium) and (Famer.Seed is small) then (Farmer.Yield is Medium) (1)

3. If (Farmer.Farmland is High) and (Farmer.Manpower is High) and (Famer.Seed is High) then (Farmer.Yield is High) (1)

4. If (Farmer.Farmland is Medium) and (Farmer.Manpower is High) and (Famer.Seed is High) then (Farmer.Yield is High) (1)

5. If (Farmer.Farmland is small) and (Farmer.Manpower is High) and (Famer.Seed is medium) then (Farmer.Yield is High) (1)

6. If (Farmer.Farmland is High) and (Farmer.Manpower is Low) and (Famer.Seed is small) then (Farmer.Yield is Small) (1)

7. If (Farmer.Farmland is Medium) and (Farmer.Manpower is Low) and (Famer.Seed is medium) then (Farmer.Yield is Small) (1)

8. If (Farmer.Farmland is Medium) and (Farmer.Manpower is High) and (Famer.Seed is High) then (Farmer.Yield is Small) (1)

9. If (Farmer.Farmland is Medium) and (Farmer.Manpower is Medium) and (Famer.Seed is High) then (Farmer.Yield is Small) (1)

10. If (Farmer.Farmland is High) and (Farmer.Manpower is Low) and (Famer.Seed is medium) then (Farmer.Yield is Small) (1)

Figure 2 Rule Base for Farmer Fuzzy Subsystem

\section{Government Rules Fuzzy Subsystem}

1. If (Farmer.Supply is Small) and (Customer.Demand is small) then (Approval_Rate is Small) (1)
2. If (Farmer.Supply is Small) and (Customer.Demand is Medium) then (Approval_Rate is Medium) (1)
3. If (Farmer.Supply is Small) and (Customer.Demand is High) then (Approval_Rate is High) (1)
4. If (Farmer.Supply is Medium) and (Customer.Demand is small) then (Approval_Rate is Small) (1)
5. If (Farmer.Supply is Medium) and (Customer.Demand is Medium) then (Approval_Rate is Medium) (1)
6. If (Farmer.Supply is Medium) and (Customer.Demand is High) then (Approval_Rate is High) (1)
7. If (Farmer.Supply is High) and (Customer.Demand is small) then (Approval_Rate is Small) (1)
8. If (Farmer.Supply is High) and (Customer.Demand is Medium) then (Approval_Rate is Medium) (1)
9. If (Farmer.Supply is High) and (Customer.Demand is High) then (Approval_Rate is High) (1)

Figure 3 Rule base for Government Fuzzy subsystem

\section{Consumer Rules Fuzzy Subsystem}

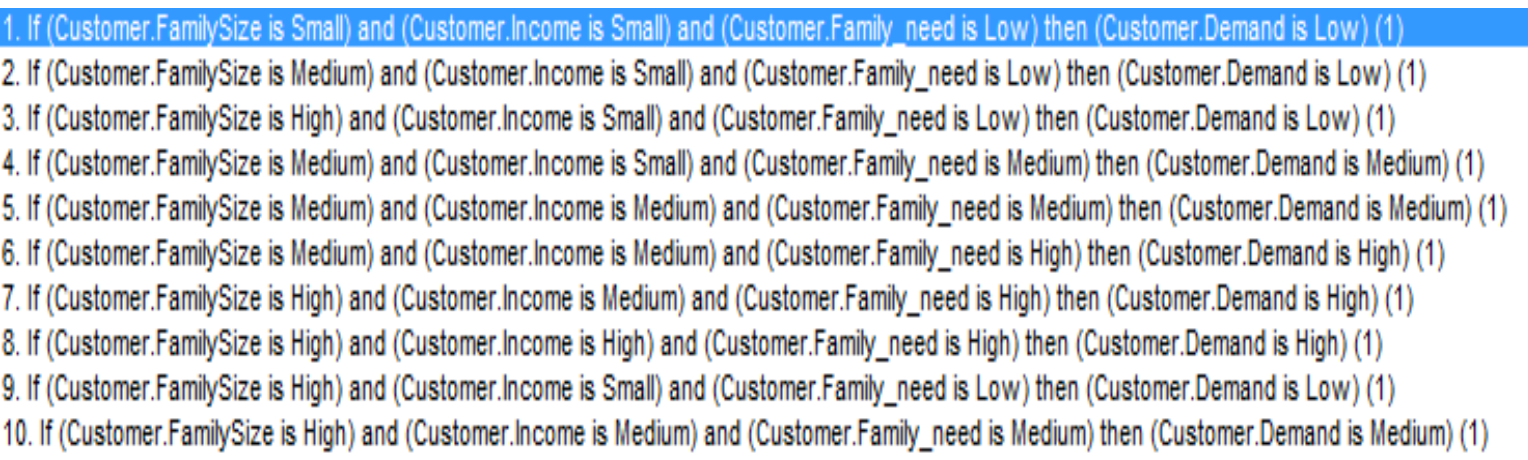

Figure 4 Rule base for Consumer Fuzzy Subsystem

The output variable namely Yields, Approval Rate and Demand are set to a membership function, Gaussian function as it is relatively easier for defuzzification process. He input variables for all the three systems are set to more than one membership function trapezoidal and triangular as it is simpler for fuzzification process. 


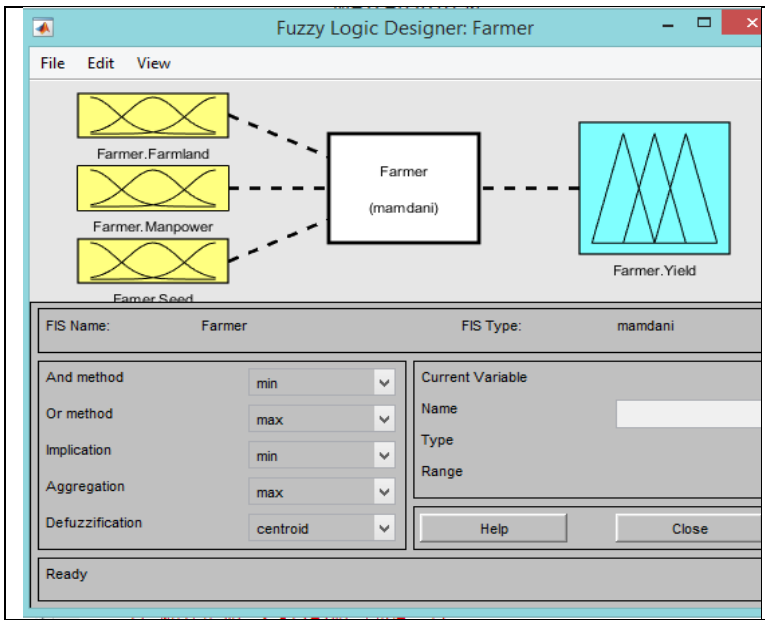

Figure 5a

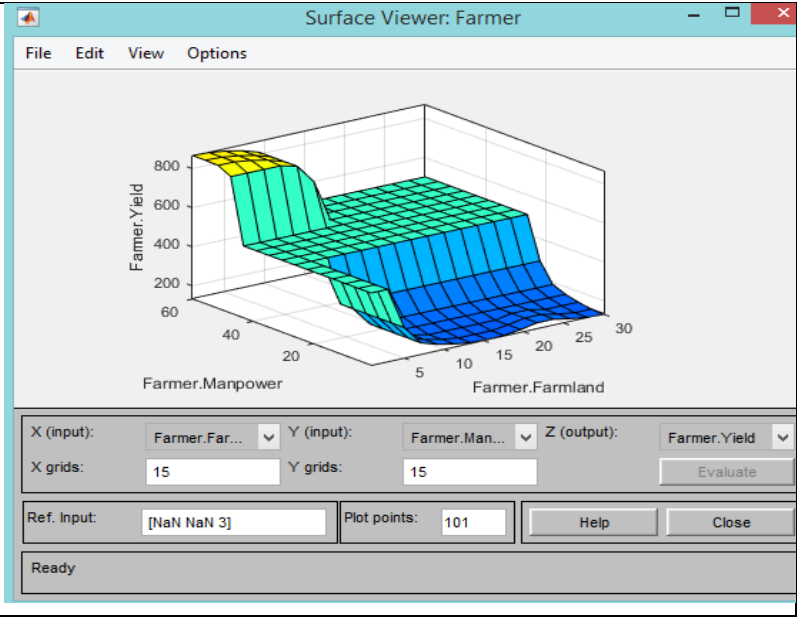

Figure 5b

Figure 5b. Output Surface generated by 5(a)

Figure 5a. Farmer Mamdami fuzzy inference system(FI system)

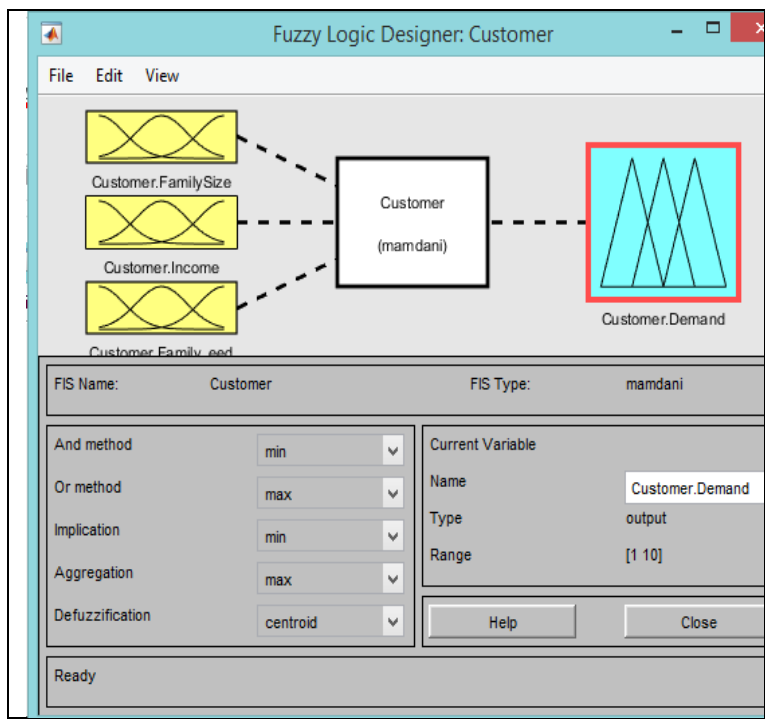

Figure 6a

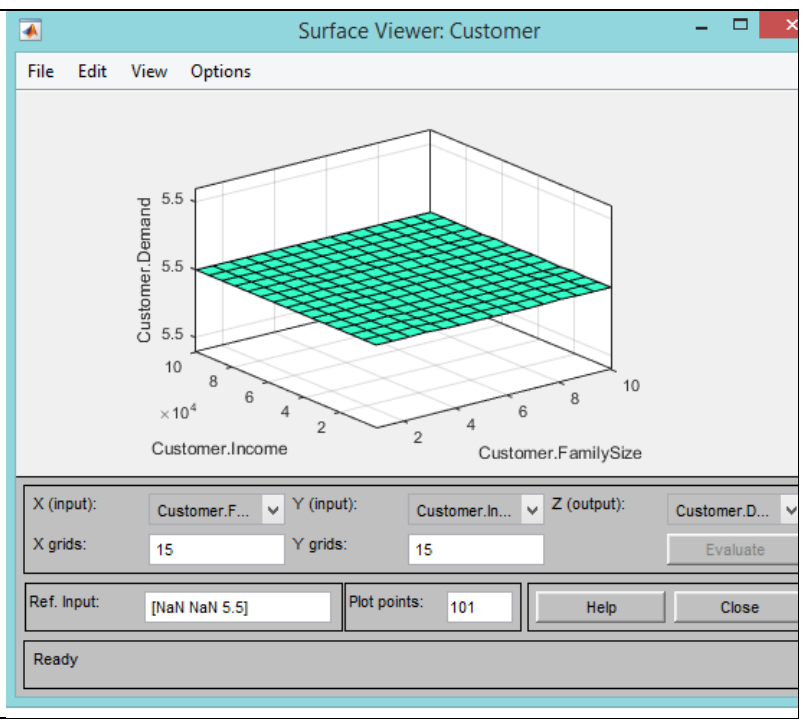

Figure 6b

Figure 6a. Consumer Mamdami fuzzy inference system(FI system) Figure 6b. Output Surface generated by 6(a)

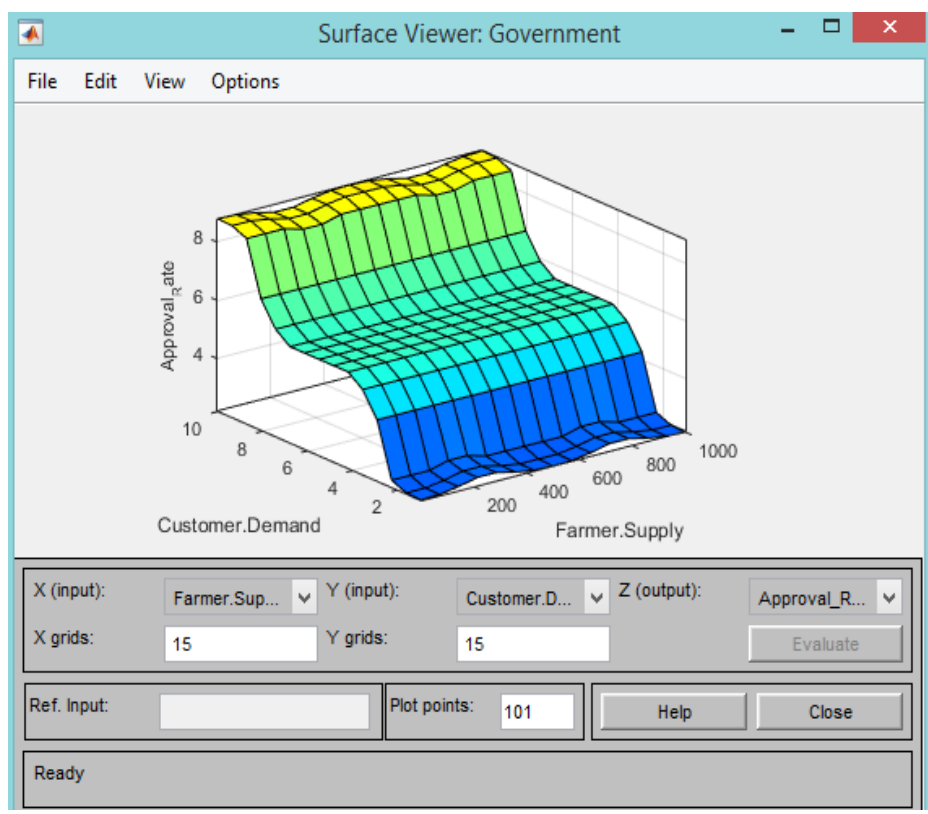

Figure 7: Surface view for the government entity given the farmer and consumer status 


\section{Conclusion and remarks}

The result in figure 7 is the sample for the solution surface for the possible rules shown in the figure 5 and 6 . This establishes the existence of the solutions for the fuzzy values through rules fired in the consumer and farmer fuzzy subsystems. The prelude for bigger public systems' requirements in terms of fuzzy logic is established and the model rules are enumerated. The rules obtained can be fine-tuned with practical and real time ranges of linguistic variables identified. However the nature of the study should involve further field work in the assigned mass with allocated resources. This model paves a possible eye opener for yet another fair system in the public domain.

\section{References}

[1] Meher Taj. S and Kumaravel A. 2015. Survey on Fuzzy Petri Net for Classification. Indian Journal of Science and Technology, 8(14)

[2] Sari, I. U., Ugurlu, S., \& Kahraman, C. (2014). Prioritization of Supply Chain Performance Measurement Factors by a Fuzzy Multicriteria Approach. In Applications of Multi-Criteria and Game Theory Approaches (pp. 161-180). Springer London.

[3] Senvar, O., Tuzkaya, U. R., \& Kahraman, C. (2014). Supply Chain Performance Measurement: An Integrated DEMATEL and Fuzzy-ANP Approach. In Supply Chain Management Under Fuzziness (pp. 143-165). Springer Berlin Heidelberg

[4] L. I. U. Yongsheng and W. E. I. Xuan, "Food supply chain risk management situation evaluation model based on factor analysis," International Business and Management, vol. 12, no. 2, pp. 40-46, 2016.

[5] L. Gong and C. Jin, "Fuzzy comprehensive evaluation for carrying capacity of regional water resources," Water Resources Management, vol. 23 , no. 12 , pp. $2505-2513,2009$

[6] D. K. Casey, "Tree puzzles of private governance: global gap and the regulation of food safety and quality," SSRN Electronic Journal, 2009.

[7] Castillo, O. and P. Melin, "Type-2 Fuzzy Logic Theory and Applications," SpringerVerlag, Berlin, 2008

[8] Dubois, D. and H. Prade, Fuzzy Sets and Systems: Theory and Applications, Academic Press, NY, 1980.

[9] Doctor, F., Hagras, H., Callaghan, V., "A Type-2 Fuzzy Embedded Agent to Realise Ambient Intelligence in Ubiquitous Computing Environments," Information Sciences, vol. 171, pp. 309-334, 2005.

[10] Lucas, L. A., T. M. Centeno and M. R. Delgado, "General Type-2 Fuzzy Inference Systems: Analysis, Design and Computational Aspects," Proc. IEEE FUZZ Conference, pp. 1107-1112, London, UK, July 2007.

[11] L.A. Zadeh, "Fuzzy Sets," Information and Control, June 1965, pp. 338-353.Google ScholarCross Ref

[12] L.A. Zadeh, "Outline of a New Approach to the Analysis of Complex Systems and Decision Processes," IEEE Trans. Systems, Man and Cybernetics, 1973, pp. 28-44. 